\title{
Mapping Urban Vulnerability: the Case Study of Gran Santo Domingo, Dominican Republic
}

\author{
Marina Rigillo ${ }^{1, a}$, Elena Cervelli ${ }^{1, b}$ \\ ${ }^{1}$ via Forno Vecchio 34, 80136, Naples, Italy \\ amarina.rigillo@unina.it, be_cervelli@yahoo.it
}

Keywords: Urban Vulnerability, Seismic Hazard, Element at Risk, GIS Mapping .

\begin{abstract}
The paper discusses research criteria for mapping urban vulnerability, focusing on the elements at risk. The study works in the framework of the "case-study research" and takes in account the impacts of a specific hazard risk (seismic event) in the City of Gran Santo Domingo, Dominican Republic. The paper proposes a critical framework that addresses planning methods toward a more efficient support to face seismic hazard.

The research question is how vulnerable are contemporary cities? And, is it possible to promote city resistance through more adequate knowledge about the assets at risk? So the study starts from the concept of risk as combination of hazard, vulnerability and exposure and propose a risk oriented methodology aimed at collecting and interpreting data about the comprehensive vulnerability of the city. Based on innovative structure of a dedicated GIS inventory, the model describes the elements at risk by a set of specific applying indicators purposely selected in order to mapping the exposure of the city to a seismic hazard and to represent urban vulnerability.
\end{abstract}

\section{Introduction}

Large-scale disasters affect communities and cities in vary different way all around the world. Natural disasters, global warming, the spread out of deadly infectious diseases are recognized as crucial crisis to the objectives of development. The costs of such disasters urge the major International Bodies (UN, World Bank, European Union) to work together to develop policies, methodologies and operational tools to mitigate the effects of disasters and to reduce risk potential $[1,2,3,4,5,6,7,8]$.

According to this, the 2014 World Development Report points out an innovative approach to risk, demonstrating a range of opportunities related to improving efficiency in risk management. The main change concern the cultural approach to risk, passing from ex post strategies - aimed at facing disaster consequences - to a proactive, systematic and integrated risk management working as ex ante approach for reducing the effects of disaster. Effectiveness in risk prevention and risk mitigation become keywords to save human lives, to reduce both social distress and economic losses and to foster coping capacity locally [9].

More specifically, the discussion within scholar community highlights the importance of updating risk definition giving scientific evidence to the relationship among hazard typology, site vulnerability and expected losses. Complexity in such definition of risk corresponds to the high variability of risk definition itself due to the hazard typology (natural hazard, industrial hazard) and because of the "case by case" characteristics of the elements at risk, including the specificity of the territory affected by. The debate focuses on the capacity of identify risk situation and of foreseeing - and estimating - the impact on urban population and assets. Major studies demonstrate that single type of risk create distinctive pattern of loss, so that the direct and indirect costs of the impacts of disaster depend by disaster typology $[10,11]$ and from the comprehensive vulnerability of the city.

Further, the expected losses in case of disaster vary due to both the dangerousness of the event and the capacity of the territory of absorbing impacts. At urban level, the goal of reaching effectiveness in risk management is deeply connected to the preparedness of the city including social awareness, economic activities and the specific features of the urban form such as land use, urban pattern, construction typologies. 
From such perspective, research advances in risk mitigation point out the contribution of planning $[12,13,14]$. Planning supports city to cope with disaster through the development of evacuation plans and due to the improvement of post-disaster management plans. However planning could have an additional role in remodeling more resistant (and resilient) cities, working both on the physical environment and on the social capacity of coping disaster [2]. Despite there is not a common understanding about the importance of planning in downgrading risk potential [15], oriented land use and the effective distribution of the urban activities are key factors for preventing major destruction, for reducing direct losses (human lives, specially) and for accelerating reconstruction.

Another important line of research aims at including urban vulnerability as critical topic in risk mitigation. Studies done by the University of Tokyo in the framework of the Centre for Sustainable Urban Redevelopment define urban vulnerability as "the most important factor in specifying an ideal form of future city" [16]. Relevance given to the urban form sets a new approach to cope risk, pointing out a more helpful role for urban design and planning in preventing risk: urban morphology, spatial distribution of household and activities, type and position of prime infrastructures are key elements to forecast - and prevent - direct losses. Lessons from the historic landscapes of Southern Italy, empirically demonstrate the importance of urban form for a (somehow implicit) risk-oriented design approach: former settlements are consistent with the need of safeguarding city from the most relevant risks existent in that contest, such as landslide and flooding because of its urban features (land use, land cover, urban pattern, building shape, construction technologies) [17]. So the minor exposure at risk of historic settlements came from the consciousness of the hazard potential at local level and of the capacity of modeling urban form in a way of preventing losses and impacts of hazard.

This kind of approach in risk prevention points out the importance of urban form as inner factor for reducing losses and for carrying out the cultural roots for a risk oriented planning method. Value, position and use of the major assets influence the city exposure and act as catalyst in case of hazard. On the contrary, knowledge about urban form and city exposure could lead toward new patterns and uses that can mitigate impacts. Planning and urban design are crucial for placing major assets and for improving spatial condition in order to facilitate population escaping in case of crisis, to reduce building crash - especially if it has primary relevance in post-disaster management - and to reduce business interruption. In terms of identifying risk situation and planning for risk management, urban vulnerability represents key information and its relevance depends to the quantity and the quality of the elements at risk and to the specific hazard.

Starting from these assumptions, the paper assumes that improving knowledge about the element at risk at city level is crucial for mapping urban vulnerability and a key part in defining risk management strategy. Due to the variability of losses - depending on the type of the hazard and the city context - urban vulnerability have to provide a set of basic data base and maps that easily represent the value of the material assets exposed at risk and to the immaterial ones (such as social values, cultural heritage, economic assets).

The paper focuses on the elements at risk in case of earthquake and proposes innovative structure for a dedicated GIS inventory, designed for achieving a number of thematic layers representing the existing asset at risk. The original contribution is the structure of the GIS inventory and the criteria for selecting indicators for evaluating the relevance of the exposure (state indicators and threshold indicators) and for monitoring urban vulnerability in the time (performance indicators). This methodology is going to be applied to the city of Gran Santo Domingo, Dominican Republic, in the framework of the EU + UN project "Estudio de la Amenanza Sismica" for enhancing capacity building in risk management.

Based on the issues and on the literature overview proposed as introduction, the paper is structured in three parts. The first one, dealing with the methodological reference and the adopted definition, is aimed at support the conceptual design of the GIS structure. The second part is focused on the case study application and highlights the specificities of the Caribbean area. The third part is structured as open conclusion aimed at discussing the future activities of the study. 


\section{Conceptual framework for setting urban vulnerability inventory}

The proposed mapping methodology organized in three parts:

1. definitions, by the aim of highlight the cultural assumption of what risk means;

2. reference, aimed at providing the scientific framework of the proposal;

3. GIS inventory, concerning the logical framework of the model for mapping vulnerability.

Definition. The study assumes the definition of risk proposed in the UNESCO Report in 1984 [18] in which risk is the combination of danger, vulnerability and exposure (Fig.1). More in deep the definition adopted are the follow:

(H) Natural Hazard, means the probability of occurrence within a specific period of time and within a given area of a potential damaging phenomenon;

(V) Vulnerability, means the degree of loss to a given element or set of elements at risk resulting from the occurrence of a natural phenomenon of a given magnitude. It is expressed in a scale from 0 (no damage) to 1 (total loss);

(Rs) Specific Risk, means the expected degree of loss due to a particular natural phenomenon. It may be expressed by the product of $\mathrm{H}$ times $\mathrm{V}$;

(E) Elements at risk means the population, properties, economic activities, including public services, etc., at risk in a given area;

(Rt) Total Risk means the expected number of lives lost, person injured, damage to property, or disruption of economic activity due to a particular natural phenomenon and it is therefore the product of Specific Risk (Rs) and Elements at Risk (E), thus:

$$
R t=(E)(R s)=(E)(H x V)
$$

In this perspective, urban area is characterized by the concentration - and value - of elements at risk that it may trigger chains of risk.

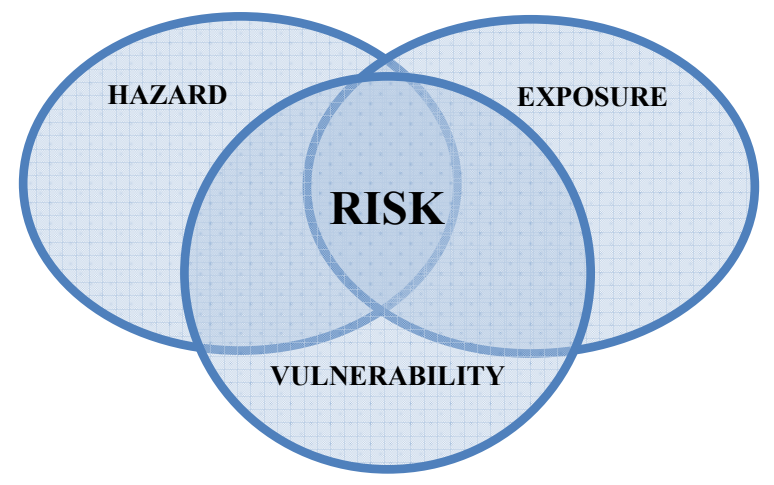

Fig. 1: Components of risk.

Methodological Reference. At international level the study refers to the UN-ISDR Report "Hyogo Framework for Action 2005-2015" [2] in which risk identification and risk assessment are recognized as milestones for sustainable and resilient cities. The report is a key reference for the study due to the relevance given to the holistic approach to risk management, including knowledge implementation, innovation technology, planning activities, local and global policies, governance of decision process.

Further the study deepens the topic of Exposure in terms of definition and measures. Because of Exposure is a variable of risk typology (natural, industrial, financial), scholars propose a wide range of indicators fit to the specificity of the research subject $[19,20,10]$. Some studies distinguish two type of Exposure: Physical Exposure related to the amount of elements at risk [14] and Systemic Exposure that deals with the relevance of single element at risk within the urban context [21]. 
Finally the study refers to the Italian Law for Risk Management [22] that defines six (6) categories of asset at risk:

1. Urban Asset: i.e. residential, commercial, settlements, scattered houses, developing area, industrial;

2. Strategic Asset: i.e. public/private hospitals, schools, Institutional buildings, military building; civic centre;

3. Primary Infrastructure: i.e. electricity, aqueducts, pipelines, motorways, railways, ports and airports, dams, hydroelectric power station;

4. Cultural and environmental asset: i.e. historic centers, archaeological area, protected area;

5. Economic activities: i.e. agriculture, crafts, public/private services;

6. Technological Plants: i.e. incinerator, landfills, chemical plants.

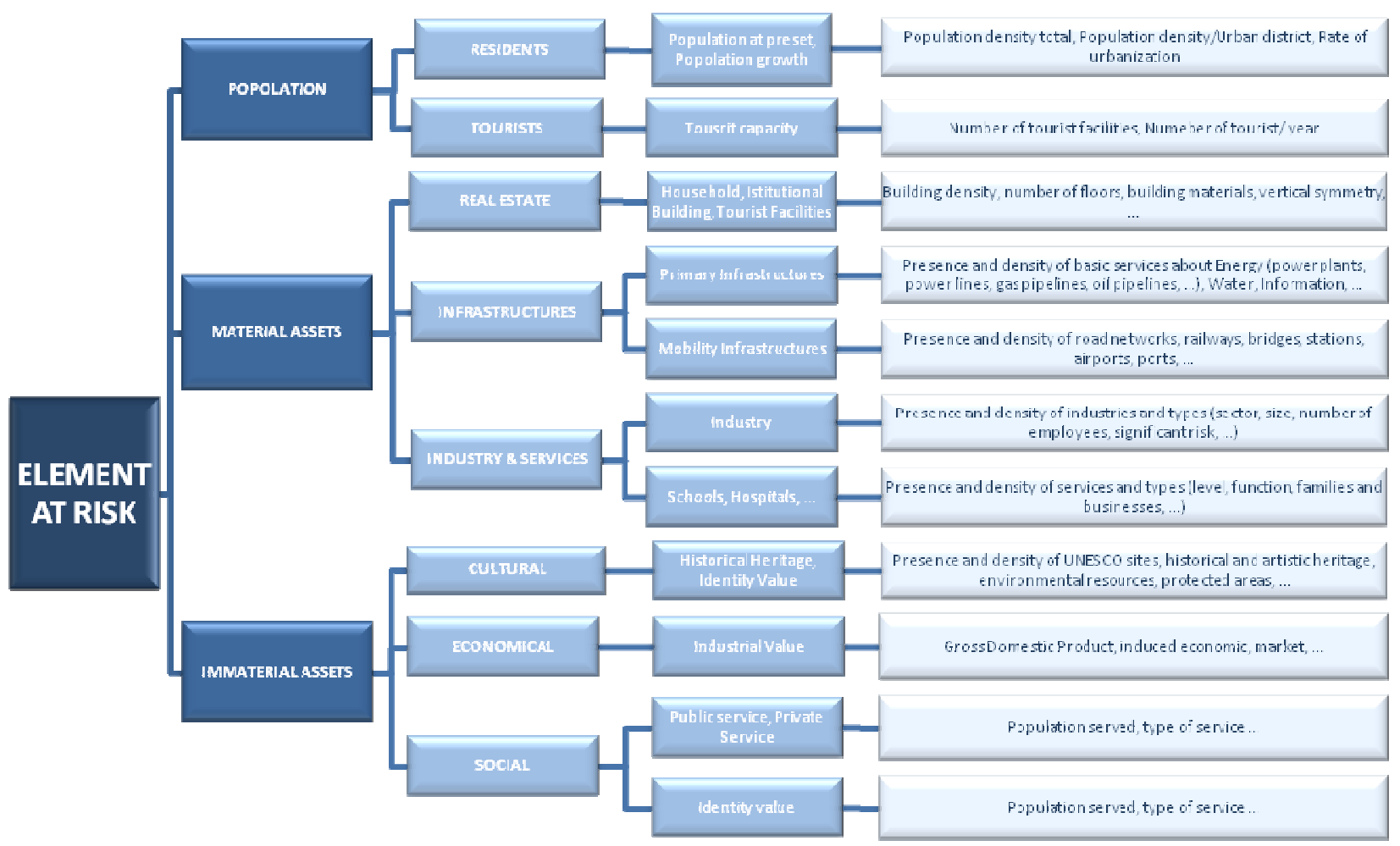

Fig. 2: GIS Inventory Structure

GIS Inventory Structure. The study proposes a five-steps methodology, aimed at defining the GIS inventory for mapping elements at risk (Fig.2).

1. Identification of the main components of the element at risk. The model considers as components the population at risk, the material loss and the immaterial loss (i.e. La ciudad colonial has both a physical component and a cultural one);

2. Sub-component and Indicators. The model provides the description of the sub components and highlights adequate indicators for each one;

3. Thematic layer production. For each indicator a raster map is carried out. Maps have produced by GIS operation (overlay, buffering, distance, spatial query, etc.) running under ARCGIS 10.2 (ESRI, Esri Headquarter, Redlands, California, USA)

4. Multi criteria evaluation. Single map is interrelated to the systemic components of the element at risk. In order to allow integrated evaluation in between adopted indicators, each map is standardized according to a common scale of values (0-1) [23]. Then specific weight 
of relevance are assigned to each value according to the importance of the losses (population, strategic asset, common assets, cultural assets, ordinary assets). The model adopts the technique of the paiwise comparision [24]. The resulting maps (Urban Comprehensive Vulnerability Map) providing information in terms of quantity and quality of the elements at risk. Maps runs under the program ILWIS 3.8.3 (52 North, ITC, Enschede, Netherlands);

5. Cluster identification. In order to manage risk specifically, a set of vulnerable urban clusters will carried out by the overlay of the element at risk and the urban morphology map. Clusters aim at providing the effective urban vulnerability of the city, focusing on those that could be considered as priority action areas for urban anti-seismic retrofitting.

The whole structure of the work is characterized by the use of SWOT analysis as decision tool support. It allows to exploit the strengths and to contain weaknesses, exploiting opportunities and assessing threats by the aim of identifying improvements for an effective seismic risk management.

\section{Overview of the Gran Santo Domingo case study}

The need to reduce the seismic risks is a real challenge for all Caribbean Countries. The Dominican Republic was the location of the worst earthquake ever registered in the Caribbean (1946, magnitude 8.1) and the Haiti earthquake in 2010 has shown the high degree of vulnerability of the region as well. The importance of the hazard potential is amplified by the features of the urban context. Urban growth has accelerated in recent years due to the high rate of urbanization: people coming from rural areas and from Haiti have occupied existing built up areas with a tendency to transform the former houses in to new buildings higher than 5 storey. This is especially true in poorer districts, where new houses or extension of existing ones has built by unskilled workers, using construction technologies not adequate for ensuring necessary earthquake proof resistance.

Recent studies demonstrate that only 30 per cent of the city is adequate to resist to the major natural hazard in the area, such as hurricane, flooding and earthquake [25]. These factors show the urgent need to promote projects aimed at increasing knowledge of seismic risk and the adoption of mitigating measures as well as on correct land use and territorial planning.

Despite the above mentioned difficulties in the building sector, Dominican Republic has adopted a national policy on risk management and created the Prevention, Mitigation and Response to Disasters National System (SNPMR). The promulgation of Law 147 [26] establishes the institutional framework and defines the public and private entities with competences to implement the processes of risk reduction, disaster preparedness and recovery to be carried out across the entire country, with the aim to protect life and property and ensure security. According to this, the General Territorial Planning Directorate (DGODT) of the Ministry of Economy, Planning and Development (MEEPyD) has also prepared a Seismic Risk Reduction Plan that has become part of the National Strategy and linking the strategies and actions to reduce the loss of human life, infrastructural damages and negative economic impact.

In this framework, the study aimed at providing effective tools and methodologies for supporting the public and private entities involved in urban planning and in the construction sectors to face a "BIG ONE" event. The project is part of the international project "Gran Santo Domingo Seismic Map and Vulnerability"and it has been structured on four (4) working packages (WP):

1. Seismic hazard assessment and elaboration of the seismic micro-zoning maps and associated studies (e.g. induced seismicity effects and tsunami hazard maps).

2. Qualitative Vulnerability study of a delimitated selected area within the Santo Domingo de Guzman-Federal District. In order to establish a risk element inventory inside of the selected study area, using databases and appropriate computerized tools such as GIS

3. Establishment and implementation of a set of remediation and prevention measures in order to reduce the vulnerability of the urban areas of Santo Domingo. 
4. Establishment and implementation of a mechanism to transfer know how and build the capacity of the main risk prevention actors.

As part of the activities of the WP2, the proposed methodology is aimed at designing the Urban Comprehensive Vulnerability Map. It is the overlay of three maps concerning the exposure at risk, the social vulnerability and the morphological vulnerability. According to this, the inventory of the assets exposed to risk has been focused on population (residents and tourists) and on the material and immaterial loss for the context of Santo Domingo. A special attention is given to the Unesco asset (Ciudad Colonial) considered as both cultural heritage and identity of the place.

The study aims at providing a flexible platform where elements at risk can be register and easily updated in a set of thematic exposure maps or can be overlaid to social vulnerability and morphological vulnerability for achieving the Urban Comprehensive Vulnerability Map.

\section{Discussion and take away for practices}

In the perspective of an "open research agenda", a brief conclusion is possible. Weakness of the proposed methodology is in the difficulty of collecting data about the element at risk and in the complexity of the simulative approach for the evaluation step. Current knowledge and developments of ITC technology for planning allow to manage a lot of information that became part of the decision-making process. Activities done in the framework of assessing the GIS inventory model deal with data collecting (focusing on the components of population and material asset) and data representation (a number of layers dealing with the above mentioned components have carried out), aiming at the empiric demonstration of application of the designed GIS inventory structure.

The first experience of mapping overlay shows that the mapping methodology is consistent with the objectives of the study and provides effective information about potential vulnerability of the major assets at risk in Gran Santo Domingo.

\section{Acknowledgements}

The Authors would like to thank Irat-CNR for the opportunity given to us for publishing part of the research work done under the project "Gran Santo Domingo Seismic Map and Vulnerability" CRIS FED/2012/24179 funded by the European Union by the aim of reducing vulnerability of the city of Santo Domingo and for strengthening resilience of the city in case of earthquake.

The study has carried out by the UN-Development Program with Istituto di Ricerca Attività Terziarie (Irat) of the National Research Council, the Bureau de Reserches Géologiques et Miniéres (BRGM) and the Istituto Geologico y Minero de Espana (IGME).

\section{References}

[1] OECD: Innovation in Country Risk Mangement. Studies in Risk Management, OECD, Paris (2009)

[2] UN-ISDR: Hyogo Framework for Action 2005-2015: Building the Resilience of Nations and Communities to Disasters, Geneva, Switzerland (2005), information on http://www.unisdr.org.

[3] UN-ISDR: Global Assessment Report on Disaster Risk Reduction: Invest Today for a Safer Tomorrow, United Nations, Geneva (2009)

[4] UN-ISDR: Global Assessment Report on Disaster Risk Reduction: Revealing Risks, Redefining Development, United Nations, Geneva, Switzerland (2009)

[5] P. Keefer, E. Neumayer, T. Plumper: Earthquake propensity and the politics of mortality prevention, edited by World Bank (2010), information on http://econ.worldbank.org/

[6] F. Shah, F. Ranghieri: A work book on planning for urban resilience in the face of disasters: adapting experiences from Vietnam's cities to other cities, edited by World Bank (2012), information on http://econ.worldbank.org. 
[7] H. Brecht, U. Deichmann, H.G. Wang: A global urban risk index, edited by World Bank (2013), information on http://econ.worldbank.org/

[8] World Economic Forum: Global Risks 2007: A Global Risk Network Report. Geneva, Switzerland (2007)

[9] World Development Reports: Risk and Opportunity. Managing risk for development, (2014), information on: http://econ.worldbank.org/WBSITE/EXTERNAL/EXTDEC/EXTRE SEARCH/EXTWDRS/EXTNWDR2013/0,,contentMDK:23330018 pagePK:8258258 piPK:8 258412 theSitePK:8258025,00.html/

[10] S. Hallegatte, V. Przyluski: The Economics of Natural Disaster (2010), information on: https://openknowledge.worldbank.org/bitstream/handle/10986/3991/WPS5507.pdf?sequence=1

[11] K. Smith: Environmental Hazards: Assessing Risk and Reducing Disaster, Routledge (2009)

[12] T. Kidokoro, J. Okata, S. Matsumura, N. Shima: Vulnerable Cities: Realities, Innovation and Strategies, Springer (2008)

[13] P. Berque, T. Beatley: Planning for earthquake, risk, politics and policy, John Hopkins University Press, Baltimora (1991)

[14] I. Cremonini (edited by): Rischio sismico e pianificazione nei centri storici, IMU Emilia Romagna (1994)

[15] S. Greiving, M. Fleischhauer, S. Wanczura: Management of natural hazard in Europe: the role of spatial planning in selected EU member states. Journal of Environmental Planning and Management, Vol. 49, Issue 5, Taylor \& Francis (2006)

[16] Information on http://csur.t.u-tokyo.ac.jp/research/vulnerable_urban_en.html/

[17] M. Rigillo, M. Clemente, G. Esposito, S. Gilchriest: Urban Form and City Environment. A proposed Methodology for understanding sustainability, edited by P. DeJoanna, D. Francese, Passaro (edited by): Sustainable Mediterrean Construction, vol. I Franco Angeli editore, ISBN 9788820414368 (2012), pp. 312-324

[18] D. J. Varnes \& International Association of Engineering Geology (IAEG): Landslide hazard zonation: a review of principles and practice, UNESCO Report (1984)

[19] R. Davidson: A multidisciplinary urban earthquake disaster risk index. Earthquake Spectra, 13(2), (1997) pp. 211-223.

[20] O. Cardona: Indicators of Disaster Risk and Risk Management: Program for Latin America and the Carribean, Main Technical Report. Washington, DC: Inter-American Development Bank (IDB) (2005)

[21] R. Fistola: Sistema Urbano e Vulnerabilità (2010), Information on http://www.romano fistola.it/vsut2.pdf/

[22] Italian Republic, Ministry for the Environment, Land and Sea and ISPRA and Basin Authority of national and districts river basin: Indirizzi operativi per l'attuazione della Direttiva 2007/60/CE relativa alla valutazione e alla gestione dei rischi da alluvioni con riferimento alla predisposizione delle mappe della pericolosità e del rischio di alluvioni (2013)

[23] M. A. Sharifi, V. Retsios: "Site selection for waste disposal through spatial multiple criteria decision analysis", In: Journal of telecommunications and information technology, (2004)

[24] T. L. Saaty: Theory and applications of the Analytic Netwok Process: Decision Making with Benefits, Opportunities, Costs and Risk (3rd edn), RWS Pubblications, Pittsburg, USA (2005)

[25] M. Pelling, The vulnerability of cities. Natural disaster and social resilience, Earthscan Publication, U.K. (2003)

[26] Dominican Republic, Law 147: Sobre Gestión de Riesgos (2002) 